molecules and sulphur. So the recent discovery of an abundance of rhodopsin-bearing bacteria in the open ocean is interesting, but not quite as Earth-shaking as portrayed here.

Similarly, the much-touted independence from solar energy of the peculiar animals that flourish around deep-sea hydrothermal vents overlooks the fact that, although they might not be fed by chlorophyll-driven photosynthesis, they are certainly breathing its waste product, oxygen. Indeed, they are as dependent on chlorophyll as all the other animals living under the Sun, down to the depths of

\section{A right whale, by Richard Ellis.}

\section{the deepest trenches.}

The book provides a healthy mixture of good and bad news from the sea. Hopefully, its portrayal of wondrous worlds inhabited by all manner of huge and strange animals will attract the public and draw muchneeded attention to the ongoing harm being inflicted on the oceans. Serious readers looking for more information may be turned off by the overpowering hyperbole, the eclectic selection of topics, and the giddy leaps from one to another.

Victor Smetacek is professor of bio-oceanography at the University of Bremen and is based at the Alfred Wegener Institute for Polar and Marine Research, 27574 Bremerhaven, Germany.

\title{
Seeing the light
}

\section{Dan Flavin experimented with fluorescent tubes to create his art.}

\section{Martin Kemp}

The US artist Dan Flavin (1933-96) made his lightworks predominantly using standard fluorescent tubes in five colours: red, yellow, blue, pink and green, as well as shades of white. These prosaic objects seem to provide only a basic means to achieve a limited end. Yet he aimed for nothing less than 'blank magic' - with 'blank' alluding to the plain, even banal, nature of the manufactured components he uses.

The magic lies in the extraordinary elusiveness of colour perception, particularly the effects of ambient colour, after-images, induced colours and complementary contrasts. Flavin's simple but artful arrays of glowing tubes present an extraordinary experimental field for anyone interested in the wonderful subtleties of coloured light and shadows. Yet they are experiments without any apparent theory. He was a true 'empiric' in the ancient sense, trying things to seewhat happened, what worked and what didn't, learning from experience but developing no theory of causes and no system for predicting effects. He was aware of the basic theories of complementary colours (which are different for pigments and for lights) and after-images, but he never dwelt on these or other theoretical aspects of colour in his writings or interviews.

Seemingly, Flavin felt that a set theory would have led to him doing the predictable, with his art, resembling those didactic demonstrations seen in science fairs, museums and exploratoriums. Indeed, at a Flavin exhibition now showing in London, scientists Mark Lythgoe, R. Beau Lotto and Mark Miodownik have devised an informative room of demonstrations of just this kind, looking at phenomena

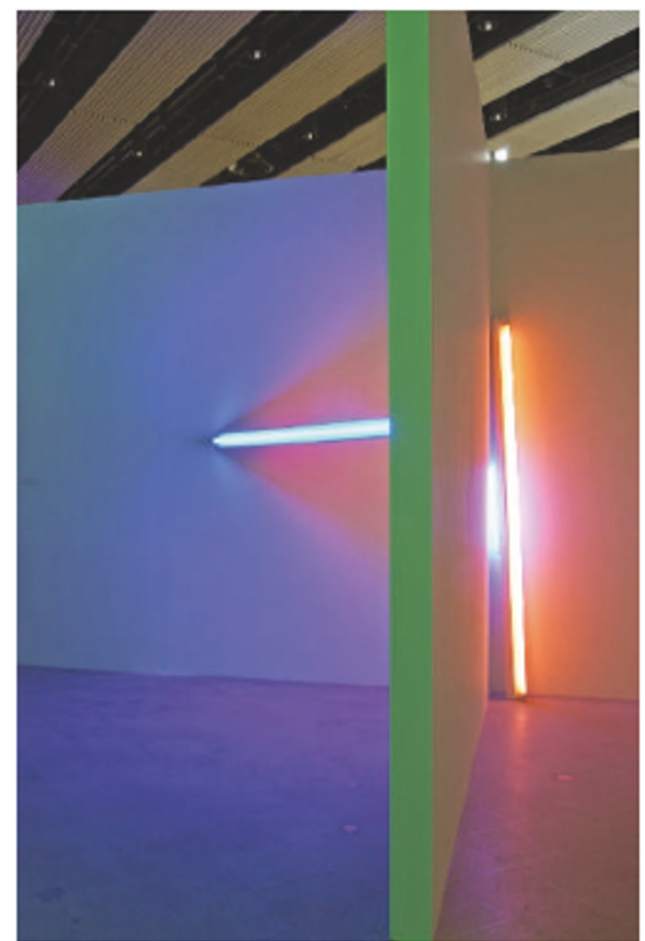

Light on theory: Dan Flavin's experiments with colour were empirical rather than systematic.

of colour and fluorescence.

In experimentally seeking the unknown, rather than merely repeating what is known to work, Flavin behaved like a scientist. But he stopped at his 'blank magic', never trying to propose anything more general beyond the specific experience - and this separates his work from the scientific. He serves up an elusive interpretative field, whereas Lythgoe and his colleagues provide measured demonstrations from which general principles can be adduced.

This is not to say that Flavin's work was intellectually unsophisticated. One of his works is entitled The Nominal Three (for Wm of Odkham). This refers to the medieval philosopher William of Ockham, famous for his philosophical 'razor', who advocated that plurality should not be posited unnecessarily. Ockham rejected the 'universals' favoured by his contemporaries, notably Thomas Aquinas. He argued that the only reality is that of the individuality of particular things, and that universal terms such as 'man' were simply the result of the grouping of similar things by the mind. Ockham's position appealed to Flavin, given his own insistence of the reality of the experience of something, rather than the superior reality of a universal order that supplies predictive rules.

Eventhough Flavinwas raised in an Irish Catholic family in New York, and quoted Ockham, he denied that there was any spiritual dimension in his art. However, moving round the exhibition, bathed in its soft light, with coloured shadows stalking the walls, it is difficult not to think of a church interior suffused by the glow from stained-glass windows.

Miraculous radiance was, traditionally, the manifestation of divine presence. That Flavin's chosen medium of light is immaterial (at least to our unaided senses) lends it a mysterious, even metaphysical, dimension, beyond whathe stated as his intention. His prosaic fluorescent tubes are indeed transposed into the realm of the magical. I suspect that this magic that will be familiar to any scientist who works on colour. 'Dan Flavin: A Retrospective' can be seen at the Hayward Gallery in London until 2 April, before transferring to museums in Paris and then Munich.

MartinKemp is professor of the history of art at the University of Oxford, Oxford OX11PT, UK. owww.hayward.org.uk/flavin 